\title{
Prazer e sofrimento no trabalho docente: Brasil e Portugal
}

\author{
Celina Hoffmann ${ }^{1}$ \\ ORCID: 0000-0002-6106-8995 \\ Roselaine Ruviaro Zanini ${ }^{1}$ \\ ORCID: 0000-0002-0533-2384 \\ Gilnei Luiz de Moura ${ }^{1}$ \\ ORCID: 0000-0003-4359-0365 \\ Bárbara Parnov Machado ${ }^{1}$ \\ ORCID: 0000-0003-3610-1842
}

\section{Resumo}

O cenário de trabalho do docente do magistério superior é complexo e multidimensional, já que coexistem demandas permeadas por dimensões de cunho social, político e econômico. Nessa direção, o presente estudo trata de vivências de prazer e de sofrimento no contexto do ensino universitário. Busca-se contribuir com a lacuna de estudos que abordam a tríade trabalho/saúde/doença em realidades distintas. Diante disso, por mediação da teoria da psicodinâmica do trabalho, o objetivo do estudo é comparar as vivências de prazer e de sofrimento entre docentes de uma IES brasileira e outra portuguesa. Configurase em estudo de caso explanatório, de abordagem quantitativa. Como instrumento de coleta de dados, foi utilizado o Inventário sobre Trabalho e Riscos de Adoecimento (ITRA), desenvolvido e validado pelos grupos: Estudos e Pesquisas em Ergonomia Aplicada ao Setor Público (ErgoPublic) e Estudos e Pesquisas em Saúde e Trabalho (Gepsat) do Instituto de Psicologia da Universidade de Brasília. Foram obtidas 326 respostas (sendo 251 de participantes brasileiros e 75, portugueses). Os escores revelaram realidade mais favorável aos respondentes da IES brasileira, enquanto a análise de cluster identificou a predominância de percepções semelhantes a respeito das vivências de prazer e de sofrimento. Além disso, destacam-se pontos comuns relacionados ao custo cognitivo, avaliado em nível grave e o custo físico, em nível crítico. Esses resultados transcendem os contextos locais e podem referir-se à categoria profissional relacionada à docência no âmbito universitário.

\section{Palavras-chave}

Prazer e sofrimento - Produtivismo - Análise de cluster - Trabalho docente.

1- Universidade Federal de Santa Maria (UFSM). Santa Maria, RS, Brasil.

Contatos: celina_hoffmann@hotmail.com; rrzanini63@gmail.com; mr.gmoura.ufsm@gmail.com; barbara.parnovm@gmail.com.

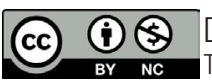




\section{Pleasure and suffering in the teaching work: Brazil and Portugal}

\section{Abstract}

The work setting of teachers in higher education is complex and multidimensional, since it coexists with several demands permeated by social, political, and economic dimensions. This article examines with experiences of pleasure and suffering in higher education teaching. It is therefore an effort to contribute to fill the gap of studies on the triad work/ health/disease in different realities. In sight of that, utilizing the theory on psychodynamics of work, this study compared the experiences of pleasure and suffering between professors of two institutions, one in Brazil and the other in Portugal. The method used was an explanatory case study, with a quantitative approach. Data collection involved the Inventory on Work and Risk of Illness (ITRA), developed and validated by ErgoPublic and Gepsat, two interdisciplinary groups of studies and research of the Institute of Psychology of the University of Brasilia (UnB). In the whole, the survey included 326 professors (251 from Brazil and 75 from Portugal). The scores revealed a more favorable reality for Brazilian professors, while the cluster analysis identified the predominance of similar perceptions regarding the experiences of pleasure and suffering. In addition, both share outstanding elements related to (i) the cognitive cost, evaluated as being of serious level; and (ii) the physical cost, evaluated as being of critical level. Thus, these results transcend local contexts and may comprehend the professional category in relation to teaching in higher education.

\section{Keywords}

Pleasure and suffering - Productivism - Cluster analysis - Teaching work.

\section{Introdução}

0 contexto de trabalho do docente do magistério superior é complexo e multidimensional. Existem demandas permeadas por dimensões de cunho social, político e econômico. Esse cenário tem levado à reconfiguração e à intensificação do trabalho docente nas Universidades, que passaram a ter de lidar com novas exigências impostas pelo ambiente de constantes inovações tecnológicas, conforme lembram Koetz et al. (2013, p. 1027) “[...] o desafio de serem educadores num momento aonde as tecnologias permitem um fluxo tão intenso de comunicação que exige constante formação”.

Os fatores causais têm sido relacionados aos pressupostos do gerencialismo, ideologia propulsora da chamada New Public Management, que prioriza elementos do setor privado aplicados ao Estado, como a busca pela eficiência, qualidade e metas organizacionais em detrimento dos processos. Nesse aparato, inclui-se a utilização de 
indicadores quantitativos para mensurar o desempenho das universidades, dos cursos de graduação e de pós-graduação (NEWMAN; CLARKE, 2012; MAGRO; SOUZA PINTO, 2012). Além disso, destacam-se as políticas adotadas a partir da década de noventa, com advento do plano de Reestruturação e Expansão das Universidades Federais (Reuni) e o Programa Universidades para Todos (Prouni).

Pesquisas recentes têm enfatizado o produtivismo como fator preponderante para o adoecimento no âmbito do magistério superior (CRUZ; LEMOS, 2005; PITA, 2010; LIMA; LIMA-FILHO, 2009). Nesse contexto, a abordagem voltada à psicodinâmica do trabalho, conceituada como a teoria crítica do trabalho, tem sido utilizada como meio de compreensão da relação trabalho - doença sob o viés das vivências de prazer e de sofrimento inerentes aos processos de subjetivação do trabalhador docente (MENDES, 2007; SILVA; MAFRA, 2014).

No entanto, faltam estudos que tratem da tríade trabalho/saúde/doença no contexto docente a partir de contextos distintos em termos sociais, culturais e econômicos. Diante disso, o presente artigo teve como objetivo comparar as vivências de prazer e de sofrimento entre docentes de uma IES brasileira e outra portuguesa. Destaca-se que o presente artigo é oriundo de dissertação de mestrado, que teve como contexto de objeto de análise o produtivismo, a partir do qual se buscou transcender as fronteiras locais como forma de contribuição incremental, aqui subsidiada pelos pressupostos da psicodinâmica do trabalho. Para tanto, utilizou-se o Inventário sobre Trabalho e Riscos de Adoecimento (ITRA), instrumento desenvolvido e validado pelos grupos: Estudos e Pesquisas em Ergonomia Aplicada ao Setor Público (ErgoPublic) e Estudos e Pesquisas em Saúde e Trabalho (Gepsat), do Instituto de Psicologia da Universidade de Brasília (MENDES; FERREIRA, 2007).

\section{Referencial teórico}

Ao considerar os conceitos subjacentes à temática, o referencial teórico está subdivido nos seguintes tópicos: a) 0 trabalho docente no ensino superior; b) A intensificação do trabalho docente; c) Aspectos a considerar sobre Brasil e Portugal; e d) A abordagem da psicodinâmica do trabalho no contexto universitário.

\section{O trabalho docente no ensino superior}

0 trabalho docente no contexto do ensino superior inclui atividades de produção e disseminação de conhecimento, participação em reuniões e colegiados, orientações, publicações em congressos e periódicos, características que o fazem exemplo emblemático do trabalho imaterial, cujo resultado é o conhecimento.

Ao percorrer as nuances do ofício docente no contexto universitário, Freitas (2007, p. 188) descreve com perspicácia: "a vida acadêmica tem na sua essência a busca e o contato com outros universos de ideias, de autores, de lugares e de temas, que favorecem uma rica vida interior". Nesse contexto, inclui-se a troca de ideias com os pares, o trabalho em equipe e o contato com alunos, além das vivências permeadas pelo constante aprimoramento intelectual. 
0 caráter imaterial do trabalho docente admite a investidura do "[...] afeto e do intelecto desse trabalhador em seu campo de atuação e nas diversas tarefas que executa" (MANCEBO, 2013, p. 519), sendo decorrentes as impressões pessoais transmitidas às tarefas, o que torna único o fazer laboral, assim como os graus de dispêndio físico e emocional. Além disso, tem um limite pouco perceptível entre o que é trabalho e vida privada, sobretudo, quando se trata de trabalho imaterial superqualificado, que gera prazer, característico da atividade docente nas IES (SGUISSARDI; SILVA JR, 2009).

\section{A intensificação do trabalho docente}

As pesquisas de enfoque crítico-reflexivo realizadas nos últimos 10 anos têm denunciado a intensificação do trabalho docente, sobretudo quando discutem o produtivismo (BOSI, 2007; FREITAS, 2011; MACHADO; BIANCHETTI, 2011; REG0, 2014; SGUISSARDI; SILVA JR, 2009; SPINK; ALVES, 2011).

Segundo Patrus; Dantas; Shigaki (2013), o produtivismo teve sua origem no movimento americano denominado public or perish, decorrente de noções normativas de regulação da publicação com regras aos autores. No Brasil, passou a ser discutido depois de regulamentações estabelecidas nas normativas de avaliação com ênfase na dimensão quantitativa que, por meio de divulgação e rankeamento, tiveram sua finalidade deturpada (MAUÉS; MOTA JR., 2011).

A aceleração das atividades, o individualismo, a competição acirrada e a concepção de estratégias para atingir números que representam um bom desempenho recaem sobre aspectos como a mercantilização do conhecimento, conforme Trein; Rodrigues (2011, p. 776) pontuam "[...] em nossa sociedade, as coisas, as pessoas, e o próprio conhecimento científico sofrem um empuxo à mercantilização, ou seja, a subsunção de seu valor de uso ao valor de troca".

Diante disso, a profıssão docente que, ideologicamente, deveria ser coletiva assume enfoque individual (SILVA; MAFRA, 2014), uma vez que o isolamento se faz cada vez mais recorrente. Nesse contexto, as críticas ao modo de produzir conhecimento científico apontam prejuízos à ciência. Nessa direção, as discussões enfatizam a necessidade do resgate da ética para que sejam preservados os valores mais importantes da academia.

\section{Aspectos a considerar entre Brasil e Portugal}

Em relevante trabalho realizado por Bianchetti; Valle (2014), é possível verificar uma análise paralela feita entre o resgate histórico da pós-graduação brasileira mediante as mudanças ocorridas, a partir da década de 90, nas formas de gestão, avaliação e financiamento e com o chamado processo de Bolonha, ocorrido a partir da Declaração de Bolonha, na Europa, cuja proposta se alicerçou na uniformização dos sistemas de educação dos países da União Europeia, visando à mobilidade acadêmica para fomentar a competitividade internacional.

Os autores buscaram compreender os impactos decorrentes no trabalho e vida dos pesquisadores brasileiros e europeus a partir das transformações a partir de então ocorridas: 
"pesquisadores foram acomodando-se às mudanças [...], bem como às determinações contidas no Processo de Bolonha”. Os resultados apontaram que existe, não apenas no Brasil, mas também no exterior uma supervalorização da produtividade, cujos critérios de eficiência e competitividade se equiparam à lógica de mercado (BIANCHETTI; VALLE, 2014, p. 101).

Adicionalmente, no Brasil, foi criado o Programa de Apoio a Planos de Reestruturação e Expansão das Universidades Federais (Reuni), instituído pelo Decreto $n^{\circ}$ 6.096, de 24 de abril de 2007. Trata-se de uma das ações que integram o Plano de Desenvolvimento da Educação (PDE), que visa à expansão física, acadêmica e pedagógica da rede federal de educação superior. Os resultados da expansão, iniciada em 2003, são consideravelmente significativos. Os municípios que têm universidade passaram de 114, em 2003, para 237, em 2011. Desde o início da expansão, foram criadas 14 novas universidades e mais de 100 novos campi, que possibilitaram a ampliação de vagas e novos cursos (BRASIL, 2010).

Tais ações, advindas do governo federal, influenciam diretamente o trabalho do professor do magistério superior federal. Ele, então, deve se adaptar às demandas que surgem em consequência de tais medidas, como o aumento do número de alunos na classe, por professor, demandas por serviços de cunho burocrático e operacional dadas pela estrutura física e de recursos humanos precárias, provocadas pelo intenso processo expansão. Soma-se a isso, tem-se o paradigma da avaliação de desempenho pelos índices de qualidade, incutindo novo ritmo de trabalho que prioriza as atividades e processos que dão conta do desempenho satisfatório para tais índices.

A adoção de medidas quantitativas de avaliação voltadas para “[...] distribuição de recompensas e recursos (prática bastante difundida nos EUA e em outros países) está trazendo uma série de distorções [...]", inclusive para o mecanismo de reconhecimento no trabalho (REGO, 2014, p. 328). Nessa perspectiva, torna-se recorrente a busca constante pelo reconhecimento de forma autônoma que, em nível individual, é considerado uma reivindicação inseparável do comprometimento subjetivo com a tarefa, a qual, nesse caso, nem sempre está atrelada à relação aluno-professor.

A partir dessa perspectiva, ao mesmo tempo em que o trabalho docente promove liberdade para discussão de ideias, autonomia nas práticas laborais, também tem sido visto como uma atividade que impõe risco à saúde, dado ao excesso de trabalho, ritmo acelerado, competição acirrada. Essas condições, no âmbito do contexto de trabalho docente, têm sido associadas ao aparecimento de doenças crônicas, alterações de saúde física e mental. De acordo com a European Agency for Safety and Health at Work (2012), os distúrbios crônicos da saúde, muitas vezes, têm causas multifatoriais e o ambiente de trabalho pode desempenhar papel central no seu desenvolvimento.

\section{A abordagem da psicodinâmica do trabalho no contexto universitário}

A partir da década de 1990, a teoria da psicodinâmica do trabalho ficou consolidada como abordagem científica capaz de identificar os efeitos do trabalho sobre a saúde dos trabalhadores. Nesse sentido, passou a ser crucial entender a subjetividade nas relações de trabalho para manutenção da saúde (MENDES, 2007). Nessa trajetória, é preponderante a compreensão acerca do desnivel percebido entre trabalho prescrito e efetivo. A partir 
disso, os sujeitos mobilizam um conjunto de mecanismos capaz de suprir as lacunas do trabalho prescrito denominado de zelo à tarefa, que prediz a preocupação de fazer bem feito, mediante o uso da inteligência (DEJOURS, 2012).

Na perspectiva da psicodinâmica do trabalho, o estudo de caso realizado por Martins; Honório (2014), aplicado em uma instituição de ensino superior privada, localizada em Belo Horizonte no estado de Minas Gerais, verificou, por meio da utilização de duas das escalas que compõem o ITRA, a prevalência de resultados classificados como críticos a graves. Entre os dados quantitativos e qualitativos levantados, o estudo sugere que as vivências de prazer e de sofrimento podem estar relacionadas às novas formas de avaliação do ensino superior a qual impacta sobremaneira as exigências do trabalho docente.

A mobilização individual coloca à subjetividade inerente à inter-relação sujeito/ trabalho o papel de gatilho entre vivências de prazer e sofrimento, conforme explica Dejours (2012, p. 364):

0 sofrimento no trabalho começa quando, apesar de seu zelo, o trabalhador não consegue dar conta da tarefa. 0 prazer, ao contrário, começa quando, graças a seu zelo, o trabalhador consegue inventar soluções convenientes. (DEJOURS; ABDOUCHELI, 2011, p. 123).

\section{Método}

0 presente trabalho consiste em uma survey do tipo cross-sectional de caráter descritivo com vistas a identificar opiniões manifestas em determinada população (FREITAS, 2000). Nesse sentido, a estratégia de investigação tem caráter comparativo e versa a respeito das vivências de prazer e de sofrimento no trabalho, no contexto de uma IES brasileira e outra portuguesa. A perspectiva de análise está alicerçada pela teoria da psicodinâmica do trabalho.

0 período de coleta de dados ocorreu no mês de março de 2014. Foi aprovado, sob o número do parecer 494.042, emitido no dia 10 de dezembro de 2013, pelo Comitê de Ética em Pesquisa da IES brasileira a qual são vinculados os autores do presente artigo. A participação dos docentes ocorreu de forma voluntária, mediante a aceitação do Termo de Consentimento Livre e Esclarecido (TCLE) incluso no questionário aplicado.

0 questionário foi enviado para uma lista com 1.539 e-mails da IES brasileira, disponibilizada pela Pró-Reitoria de Gestão de Pessoas, na qual não constavam os e-mails de professores substitutos ou aqueles desatualizados. Da mesma forma, foi enviado para a IES portuguesa com uma lista de 1.885 e-mails de docentes, coletados diretamente no site institucional.

Foram obtidas 251 respostas dos docentes da IES brasileira e 75 de docentes da IES portuguesa. Dessa forma, para fins de análise, estimou-se o erro amostral de cada instituição, em que a primeira apresentou um erro amostral em torno de 6\% (251 entrevistados) e a segunda em torno de 11\% (75 entrevistados). 0 erro amostral, tendo sido calculado abaixo de 15\%, não invalida as análises estatísticas empregadas, que são do tipo não-paramétricas, sem necessidade de erro amostral abaixo de 5\%. Destaca-se que o presente estudo obteve uma amostra por conveniência (FREITAS, 2000), considerando 
que a baixa proporção de respondentes pode ter refletido uma maior sensibilidade ao tema em relação aos docentes que optaram por não participar da pesquisa.

Nesse sentido, os resultados deste trabalho servem como estimativas populacionais, já que manteve a aleatoriedade, no intuito de captar as variações existentes e obteve significância estatística a partir do p-valor dos testes realizados. No entanto, existe a limitação para o quesito aleatoriedade dos dados, visto que há a possibilidade de ter um viés dos participantes no momento de aceitação de responder o questionário, dado o caráter voluntário de participação.

A literatura que se dedica às temáticas subjacentes abordadas pelo presente artigo não aponta instituições de ensino superior capazes de representar o produtivismo ou mesmo o adoecimento no trabalho nos pressupostos da teoria da psicodinâmica do trabalho. Desse modo, a escolha das instituições não apresenta nenhum viés que comprometa os resultados e a imparcialidade.

A escolha entre os dois países, Brasil e Portugal, foi feita por dois motivos concomitantes: a) operacional, ocorreu por conveniência, uma vez que Portugal como um país europeu tem o mesmo idioma que o Brasil, facilitando a aplicação do instrumento de pesquisa; e b) teórico, tendo em vista a contribuição incremental às duas áreas que são temas subjacentes à pesquisa: o produtitivismo e a psicodinâmica do trabalho. Os subitens decorrentes desta seção são: participantes, instrumento, procedimentos e análise dos dados.

\section{Participantes}

A IES brasileira é uma Instituição Federal de Ensino Superior, fundada no ano de 1960 e constituída como Autarquia Educacional de Regime Especial vinculada ao Ministério da Educação. 0 campus sede está localizado em um município do sul do Brasil, no qual maior parte das atividades acadêmicas acontece. Os cursos de graduação e pósgraduação estão distribuídos entre outros três campi, localizados em municípios distintos. É composta por um total de 27.880 alunos entre cursos de nível médio, graduação e pósgraduação e 4.782 servidores, sendo 1.693 docentes vinculados ao magistério superior.

Quanto à IES portuguesa, trata-se de uma universidade pública localizada em Lisboa, capital do país. Começou sua história em 1288, quando nasceu a primeira universidade portuguesa, sendo transferida, em 1537, para Coimbra. A partir do final do século XVIII, os estudos superiores foram restabelecidos na capital, através de Cursos, Escolas e Institutos que, em 1911 e em 1930, se congregaram em duas universidades. Recentemente, em 2013, houve nova fusão. É composta por 48.066 alunos, distribuídos entre cursos de graduação e de pós-graduação, e por 3.422 docentes.

Nesta seção, são apresentados os dados a respeito do perfil sociodemográfico por meio da Tabela 1 e as características sobre carreira docente nos contextos de cada IES.

Revela-se, então, o perfil dos docentes de ambas as instituições. Os docentes da instituição brasileira são mulheres (53\%), entre 41 a 50 anos (35\%), casados (58\%) e com filhos (60\%). Enquanto os portugueses caracterizam-se também pelo perfil dos brasileiros, o que difere são os percentuais. 
Quanto à área de conhecimento a qual se dedicam, pode-se observar que nas duas universidades houve maior participação dos docentes das seguintes áreas: Ciências Exatas e da Terra, Ciências Sociais e Aplicadas e Ciências da Saúde. Quanto ao tempo dedicado ao magistério superior, verifica-se que a maioria (58\%) dos docentes brasileiros tem mais de 11 anos de carreira, enquanto que entre os portugueses esse percentual é maior (66\%). Porém, no que condiz ao tempo de vínculo, observa-se que na IES brasileira, apesar de $47 \%$ dos participantes terem vínculo menor do que 5 anos, os demais percentuais somados correspondem à maioria dos participantes com mais de 5 anos de vínculo. Já na IES portuguesa, verifica-se certo equilíbrio entre os novatos (31\%) e veteranos (33\%).

Tabela 1 - Caracterização dos respondentes

\begin{tabular}{|c|c|c|c|c|}
\hline & & IES brasileira & IES portuguesa & Total (\%) \\
\hline & & $\mathrm{n}_{1}=251(\%)$ & $\mathrm{n}_{2}=75(\%)$ & 326 \\
\hline \multirow{2}{*}{ Gênero } & Feminino & $132(53)$ & $40(54)$ & $172(53)$ \\
\hline & Masculino & $119(47)$ & $35(46)$ & $154(47)$ \\
\hline \multirow{5}{*}{ Faixa Etária } & 20 a 30 anos & $11(4)$ & $3(4)$ & $14(4)$ \\
\hline & 31 a 40 anos & 87 (35) & $16(22)$ & 103 (32) \\
\hline & 41 a 50 anos & 88 (35) & $24(32)$ & $112(34)$ \\
\hline & 51 a 60 anos & 54 (22) & $23(31)$ & 77 (24) \\
\hline & 61 anos ou mais & $11(4)$ & $9(11)$ & $20(6)$ \\
\hline \multirow{5}{*}{ Estado Civil } & Casado (a) & $145(58)$ & $49(65)$ & $194(60)$ \\
\hline & Divorciado (a) & $15(6)$ & $8(11)$ & $23(7)$ \\
\hline & Solteiro (a) & $51(20)$ & $6(8)$ & $57(17)$ \\
\hline & União Estável & $38(15)$ & $12(16)$ & $50(15)$ \\
\hline & Viúvo (a) & $2(1)$ & - & $2(1)$ \\
\hline \multirow{2}{*}{ Possui filhos } & Sim & $150(60)$ & $55(73)$ & $170(52)$ \\
\hline & Não & $101(40)$ & $20(27)$ & $156(48)$ \\
\hline
\end{tabular}

Fonte: elaboração dos autores.

\section{Instrumento e procedimentos}

0 instrumento utilizado consistiu nas escalas pertencentes ao Inventário sobre Trabalho e Riscos de Adoecimento (ITRA), instrumento desenvolvido e validado pelos grupos: Estudos e Pesquisas em Ergonomia Aplicada ao Setor Público (ErgoPublic) e Estudos e Pesquisas em Saúde e Trabalho (Gepseat), do Instituto de Psicologia da Universidade de Brasília (MENDES; FERREIRA, 2007).

0 ITRA avalia algumas dimensões da inter-relação trabalho e processos de subjetivação, sendo composto pelas seguintes escalas: a) escala de avaliação do contexto do trabalho (EACT) formada pelos fatores organização do trabalho, relações socioprofissionais e condições de trabalho; b) escala de custo humano do trabalho (ECHT), formada pelos fatores custo afetivo, custo cognitivo e custo físico; c) escala de indicadores de prazer e sofrimento no trabalho (EIPST), formada pelos fatores liberdade de expressão, realização 
profissional, esgotamento profissional e falta de reconhecimento; d) escala de avaliação dos danos relacionados ao trabalho (EADRT), formada pelos fatores danos sociais, danos psicológicos e danos físicos. A estrutura do ITRA pode ser conferida na Tabela 2.

As escalas do ITRA são compostas por variáveis qualitativas, sendo a maior parte delas divididas em gradientes de 7 pontos, com exceção da ECHT, que é de 5 pontos. De acordo com Pereira (1999), as escalas do tipo ordinal medem atributos que se distinguem em grau ou intensidade, concebidas por relações de ordem com sentido e direção definidos. A análise do ITRA, porém, não é feita com base nas variáveis categóricas ordinais, mas nos valores de média resultantes das respostas de cada sujeito, mediante os níveis de avaliação possíveis, conforme os parâmetros limítrofes preconizados pelos autores que elaboraram o inventário (MENDES; FERREIRA, 2007).

Visto que as populações das duas instituições são finitas, optou-se por enviar a todos os contatos de e-mail, de modo a atingir todos os docentes, com a finalidade de assegurar o maior número de participantes. Dessa forma, a coleta de dados ocorreu à distância, por meio da aplicação de um questionário de autopreenchimento, por meio da ferramenta do Google docs, no período entre os meses de janeiro a abril de 2014.

Tabela 2 - Descrição do Instrumento de Pesquisa ITRA

\begin{tabular}{|c|c|c|c|}
\hline Escala & Fatores & Parâmetros & Nível \\
\hline EACT & $\begin{array}{c}\text { Organização do Trabalho - OT } \\
\text { Relações Socioprofissionais- RS } \\
\text { Condições de Trabalho - CT }\end{array}$ & $\begin{array}{c}\text { Acima de 3,7 } \\
\text { Entre 2,3 e 3,69 } \\
\text { Abaixo de 2,29 }\end{array}$ & $\begin{array}{l}\text { Grave } \\
\text { Crítico } \\
\text { Satisfatório }\end{array}$ \\
\hline ECHT & $\begin{array}{l}\text { Custo Afetivo - CA } \\
\text { Custo Cognitivo- CC } \\
\text { Custo Físico - CF }\end{array}$ & $\begin{array}{c}\text { Acima de 3,7 } \\
\text { Entre 2,3 e 3,69 } \\
\text { Abaixo de 2,29 }\end{array}$ & $\begin{array}{c}\text { Grave } \\
\text { Crítico } \\
\text { Satisfatório }\end{array}$ \\
\hline EIPST $^{*}$ & $\begin{array}{l}\text { Liberdade de Expressão - LE } \\
\text { Realização Profissional - RP } \\
\text { Esgotamento Profissional - EP } \\
\text { Falta de Reconhecimento - FR }\end{array}$ & $\begin{array}{l}\text { Acima de 4,0 } \\
\text { Entre } 3,9 \text { e 2,1 } \\
\text { Abaixo de 2,0 }\end{array}$ & $\begin{array}{l}\text { Satisfatório } \\
\text { Crítico } \\
\text { Grave }\end{array}$ \\
\hline EADRT & $\begin{array}{c}\text { Danos Sociais - DS } \\
\text { Danos Psicológicos - DP } \\
\text { Danos físicos - DF }\end{array}$ & $\begin{array}{c}\text { Acima de 4,1 } \\
\text { Entre } 3,1 \text { e } 4,0 \\
\text { Entre } 2,0 \text { e } 3,0 \\
\text { Abaixo de } 1,9\end{array}$ & $\begin{array}{c}\text { Presença de doenças } \\
\text { ocupacionais } \\
\text { Grave } \\
\text { Crítico } \\
\text { Suportável }\end{array}$ \\
\hline
\end{tabular}

*Para os fatores que compõem as vivências de sofrimento os níveis de avaliação são inversos.

Fonte: Elaborado, pelos autores, com base em Mendes; Ferreira (2007). 


\section{Análise dos dados}

A análise dos resultados referentes ao ITRA foi subsidiada pelo software Statistica 9.1, por meio das médias e desvios-padrão resultantes de cada fator das escalas, conforme preconizam os autores do inventário. De forma complementar, foram realizados testes não paramétricos para análises interinstitucionais e intrainstitucionais.

Com o intuito de viabilizar as demais análises estatísticas, fez-se necessária adaptação do banco de dados original, para que, ao invés da utilização dos valores de médias individuais, pudessem ser utilizadas variáveis quantitativas que permitissem a legitimidade dos resultados, por isso foram utilizados os somatórios das respostas de cada um dos sujeitos.

Visto que o presente trabalho utilizou um instrumento de coleta de dados previamente validado, a mensuração da confiabilidadedos dadoségarantidapelo cálculo do coeficiente Alfa ( $\alpha$ ) de Cronbach, que demonstra consistência interna dos fatores do ITRA para ambos os contextos institucionais. Os mesmos são abordados na seção que pertence aos resultados.

Em termos de análise comparativa, foram realizados os seguintes métodos estatísticos não paramétricos para comparação de grupos: Mann-Whitney, visto que, por tratar-se de variáveis qualitativas, os dados não obedecem a uma distribuição normal e, por isso, os métodos relacionados mostraram-se adequados.

Adicionalmente, foi realizada análise de cluster que consiste em uma técnica de estatística multivariada, cujo objetivo é agrupar dados com base na similaridade entre os mesmos, utilizando método single linkage e medida de distância euclidiana. Dessa forma, foi possivel perceber a forma como os fatores se agruparam diante das repostas obtidas.

\section{Resultados e discussão}

0 presente artigo reúne a participação de docentes brasileiros (16\%) e portugueses (4\%), visto que a discrepância entre o número de participantes evidencia maior participação dos brasileiros. A confiabilidade dos dados é garantida pelo cálculo do coeficiente Alfa $(\alpha)$ de Cronbach, que demonstra consistência interna dos fatores do ITRA para ambos os contextos institucionais.

No contexto da IES portuguesa, foram identificados os valores de Alfa de Cronbach para cada escala: EACT $(0,83)$, ECHT $(0,65)$, EIPST $(0,86)$, EDRT $(0,84)$, assim como o Alfa de Cronbach geral $(0,78)$. Já no contexto da IES brasileira, os valores identificados foram: $\operatorname{EACT}(0,73), \operatorname{ECHT}(0,68)$, EIPST $(0,81)$, EDRT $(0,80)$, sendo o Alfa de Cronbach geral de 0,76 . Tendo em vista a complexidade das questões que o instrumento se propõe a mensurar e o intervalo de valores possíveis de 0 a 1 , o instrumento de coleta ITRA mostrou-se adequado.

Em relação aos fatores da Escala de Avaliação do Contexto do Trabalho, que são: organização do trabalho, relações socioprofissionais e condições de trabalho, apresentaram médias que retratam situação crítica nas duas universidades. 0 fator organização do trabalho apresentou maior média e seus itens incluem: o ritmo de trabalho acelerado, pressão por tempo de execução, tarefas repetitivas, cobrança e fiscalização de resultados. 
Quanto aos fatores da Escala de Avaliação do Custo Humano do Trabalho, verifica-se considerável consonância em relação aos resultados apresentados pelas duas IES. A avaliação das médias denota nível crítico para o custo afetivo e físico e nível grave para o custo cognitivo. Além disso, mediante à aplicação do teste Mann-Whitney, verifıcou-se diferença significativa do fator custo cognitivo entre os grupos.

Na Tabela 3, são apresentados os resultados da aplicação do ITRA, conforme as médias dos fatores componentes das quatro subescalas e subsidiando a análise interinstitucional.

Tabela 3 - Resultados da aplicação do ITRA e teste Mann-Whitney

\begin{tabular}{|c|c|c|c|c|}
\hline & IES & brasileira & IES & portuguesa \\
\hline & Média & $\mathrm{DP}$ & Média & DP \\
\hline Organização do Trabalho & 3,06 (crítico) & 1,20 & 3,24 (crítico) & 1,21 \\
\hline Relações Socioprofissionais & 2,65 (crítico) & 1,28 & 2,84 (crítico) & 1,36 \\
\hline Condições de Trabalho & 2,48 (crítico) & 1,28 & 2,47 (crítico) & 1,32 \\
\hline Custo Afetivo & 2,70 (crítico) & 1,23 & 2,73 (crítico) & 1,26 \\
\hline Custo Cognitivo* & 4,11 (grave) & 1,08 & 4,14 (grave) & 1,11 \\
\hline Custo Físico & 2,37 (crítico) & 1,21 & 2,37 (crítico) & 1,28 \\
\hline Liberdade de Expressão & 4,12 (satisfatório) & 1,97 & 3,78 (crítico) & 2,15 \\
\hline Realização Profissional* & 4,10 (satisfatório) & 1,93 & 4,03 (satisfatório) & 1,97 \\
\hline Esgotamento Profissional ${ }^{\star}$ & 2,79 (crítico) & 2,22 & 3,31 (crítico) & 2,38 \\
\hline Falta de Reconhecimento & 1,78 (satisfatório) & 2,10 & 2,22 (crítico) & 2,34 \\
\hline Danos Sociais & 1,55 (suportável) & 1,92 & 1,65 (suportável) & 2,17 \\
\hline Danos Psicológicos & 1,64 (suportável) & 2,02 & 1,95 (crítico) & 2,33 \\
\hline Danos Físicos & 2,21 (crítico) & 2,34 & 2,33 (crítico) & 2,38 \\
\hline
\end{tabular}

*Fatores que apresentaram diferença significativa entre os grupos $(p<0,05)$.

Fonte: elaboração dos autores.

$\mathrm{Na}$ Tabela 4, estão enumerados os dez itens formadores do fator custo cognitivo com as respectivas médias de ambas as universidades. A avaliação em nível grave do custo cognitivo denota aspecto negativo, sendo produtor de sofrimento no trabalho, com forte contribuição para o adoecimento, visto que emerge a necessidade da intervenção institucional em regular as exigências por ela impostas (MENDES; FERREIRA, 2007).

Esse resultado apresentado leva a crer que, em ambos os contextos, a sobrecarga cognitiva dada pela intensificação do trabalho docente transcende aspectos localmente contextualizados e parte de aspectos de conjuntura mundial, condizentes à valorização do trabalho imaterial, inserção de novas tecnologias e nova relação entre produção e divulgação de conhecimento. 
Tabela 4 - Médias dos itens que compõem o custo cognitivo

\begin{tabular}{ccc:ccc}
\hline \multirow{2}{*}{ Componentes do Custo Cognitivo } & \multicolumn{2}{c}{ IES brasileira } & \multicolumn{2}{c}{ IES portuguesa } \\
\cline { 2 - 5 } Desenvolver macetes & Média & DP & Média & DP \\
\hline Ter que resolver problemas & 2,42 & 1,22 & 2,24 & 1,24 \\
Ser obrigado e lidar com imprevistos & 4,29 & 0,87 & 4,25 & 0,92 \\
Fazer a previsão de acontecimentos & 4,11 & 0,89 & 4,15 & 1,11 \\
Usar a visão de forma contínua & 3,84 & 0,92 & 3,95 & 1,05 \\
Usar a memória & 4,29 & 1,04 & 4,16 & 0,74 \\
Ter desafios intelectuais & 4,44 & 0,93 & 4,44 & 0,77 \\
Fazer esforço mental & 4,47 & 0,78 & 4,59 & 0,74 \\
Ter concentração mental & 4,46 & 0,82 & 4,51 & 0,70 \\
Usar a criatividade & 4,47 & 0,82 & 4,55 & 0,88 \\
\hline
\end{tabular}

Fonte: elaboração dos autores.

Verifica-se que os itens com maiores médias foram: ter desafios intelectuais, fazer esforço mental e ter concentração mental. Tais aspectos estão estreitamente ligados à rotina de trabalho no magistério superior, tendo em vista as atividades de ensino e pesquisa que se caracterizam pela forte demanda intelectual na disseminação e construção do conhecimento.

Os fatores da Escala de Indicadores de Prazer e Sofrimento no Trabalho estão separados em fatores ligados às vivências de prazer que são: liberdade de expressão e realização profissional e fatores ligados às vivências de sofrimento que são: esgotamento profissional e falta de reconhecimento.

Dessa forma, percebe-se a relação ambivalente estabelecida entre prazer-sofrimento, que, de certa forma, coexistem no ambiente de trabalho. Nesse sentido, o trabalho é fonte de prazer quando favorece a valorização e reconhecimento pela tarefa executada e propicia ao trabalhador liberdade de adequar-se à organização do trabalho, conforme seu desejo e necessidades. Por outro lado, passa a ser fonte de sofrimento, na medida em que a relação entre sujeito e trabalho está bloqueada em que há sobrecarga ou subutilização das faculdades intelectuais, psicoafetivas, de aprendizagem e de adaptação, levando ao sofrimento.

A análise relacionada às vivências de prazer, condizente à liberdade de expressão, que reflete as possibilidades do trabalhador de pensar, organizar e falar sobre o próprio trabalho apresentou nível satisfatório na IES brasileira e, em contrapartida, na IES portuguesa, apresentou nível crítico. Quanto ao fator realização profissional, que denota a identificação e gratificação do sujeito pelo trabalho que realiza, observou-se nível satisfatório em ambas as instituições. 0 teste Mann-Whitney apresentou diferença significativa entre os grupos, ou seja, com a ressalva da avaliação satisfatória, a realização profissional para os docentes brasileiros é maior do que para os docentes portugueses. 
0 fator esgotamento profissional, como fator de avaliação das vivências de sofrimento no trabalho, reflete situações de frustração, insegurança, sobrecarga e estresse no contexto laboral (MENDES; FERREIRA, 2007). A avaliação do fator esgotamento profissional apresentou médias em nível crítico nas duas instituições, com atenção para IES portuguesa que apresentou média mais elevada em relação à brasileira, visto que a aplicação do teste Mann-Whitney apresentou diferença significativa entre os grupos.

Nesse contexto, o esgotamento profissional reflete uma organização do trabalho que impõe exigências de trabalho que se traduzem em sobrecarga. 0 resultado em nível crítico faz um alerta a essas condições, tendo em vista que também influenciam as características pessoais de cada trabalhador. Conforme Dejours (2011), para transformar um trabalho fatigante em trabalho equilibrante, é necessário que sua organização seja flexível.

Para o fator falta de reconhecimento, que condiz às vivências de sofrimento no trabalho, como situações de injustiça, indignação, desvalorização e discriminação, a avaliação das médias retratou nível satisfatório tanto para os docentes participantes brasileiros quanto para os portugueses. 0 reconhecimento no trabalho permite ao sujeito criar novo significado às vivências de sofrimento como angústias, decepções, desalentos e, dessa forma, todos os esforços por ele despendidos adquirem significado ao perceber que existe compensação (DEJOURS, 2011). Nesse sentido, o sujeito percebe-se diferente do que era antes e permite incorporar o reconhecimento à construção de sua identidade, na forma de autorrealização.

Quanto aos fatores componentes da Escala de Avaliação dos Danos relacionados ao Trabalho, que apontam as consequências trazidas por fatores físicos e psicossociais inerentes ao contexto laboral, são enumerados a partir dos danos sociais, danos psicológicos e danos físicos. De acordo com Mendes e Ferreira (2007), a análise dessa escala deve ser realizada de modo distinto, pois os itens propostos retratam situações muito graves relacionadas à saúde. Dessa forma, a análise do primeiro fator que corresponde aos danos sociais apresentou nível suportável em ambas as instituições, sugerindo que as relações pessoais e sociais não foram afetadas, tendo em vista as vivências de sofrimento.

Quanto ao fator relacionado aos danos psicológicos, os valores das médias apresentaram nível crítico na IES portuguesa e nível satisfatório na IES brasileira. Este fator relaciona-se a sentimentos negativos com relação a si mesmo ou com a vida em geral. Nesse contexto, justifica-se a crescente preocupação de pesquisadores europeus com os riscos psicossociais e suas implicações no trabalho, tendo em vista a crescente proliferação de fatores como stress, assédio moral ou sexual, além da violência entre trabalhadores europeus (EU-OSHA, 2012).

No que condiz ao fator referente aos danos físicos, observaram-se médias avaliadas em nível crítico, em ambas as instituições. Os itens avaliados correspondem à ocorrência de dores, distúrbios da saúde e alterações do sono e apetite. Nesse sentido, faz-se necessário discutir as condições de trabalho e as implicações para a saúde do docente e, apesar do trabalho exercido ser predominantemente intelectual, não quer dizer que não haja incidência de doenças relacionadas ao trabalho.

De acordo com Pita (2010, p. 15), "São muitas as doenças laborais identificadas entre docentes". A autora alerta para fatores como falta de estrutura física adequada como 
mobiliário, condições acústicas, falta de iluminação adequada e demais recursos materiais precários, que sujeitam o docente a problemas de coluna, dores musculares e distúrbios visuais. Além disso, as exigências do trabalho quanto à prática de horas extras, acúmulo de funções, pressão por prazos e desempenho geram maior custo humano provocando doenças psicossomáticas.

$\mathrm{Na}$ análise interinstitucional, além da sobrecarga cognitiva em nível grave ter sido detectada em ambos os contextos, os valores absolutos das médias de cada fator retratam realidade mais favorável aos docentes da IES brasileira em relação aos docentes da IES portuguesa, pois mesmo que muitos fatores tenham obtido a mesma avaliação, os docentes participantes portugueses atribuíram escores mais altos em direção à avaliação grave dos atributos.

Quanto aos percentuais, permitiu considerar o somatório das avaliações individuais em nível crítico e nível grave em cada instituição. No contexto da IES brasileira, os maiores percentuais identificados foram: organização do trabalho (84\%) e custo cognitivo (97\%). Da mesma forma, na IES portuguesa: organização do trabalho (81\%), custo cognitivo (100\%) e custo afetivo (96\%).

Nesse sentido, apesar do custo afetivo ter apresentado média em nível crítico para os docentes da IES portuguesa, ao considerar as avaliações em nível grave, surge como fator relevante na contribuição para as vivências de sofrimento. Adicionalmente, vale ressaltar que o custo cognitivo entre os docentes da IES portuguesa teve avaliação grave ou crítica, ou seja, nenhum dos docentes participantes apresentou avaliação em nível satisfatório. Outro aspecto que merece atenção é o fator organização do trabalho que coincide nas duas universidades como fator que contribui para as vivências de sofrimento.

Quanto aos indícios de presença de doenças são retratados pelas avaliações mais graves dos fatores da escala sobre danos relacionados ao trabalho, por isso exigem muita atenção. Nesse contexto, faz-se importante detalhar o nível de avaliação que evidencia presença de doenças, conforme a tabela 5.

Tabela 5 - Frequência absoluta e relativa para o nível de avaliação presença de doenças

\begin{tabular}{|c|c|c|}
\hline Fator & $\begin{array}{l}\text { IES brasileira } \\
\text { frequência (\%) }\end{array}$ & $\begin{array}{l}\text { IES portuguesa } \\
\text { frequência (\%) }\end{array}$ \\
\hline Danos sociais & $28(11)$ & $11(15)$ \\
\hline Danos psicológicos & $21(8)$ & $10(13)$ \\
\hline Danos físicos & $28(11)$ & $14(19)$ \\
\hline Total & $77(30)$ & $35(47)$ \\
\hline
\end{tabular}

Fonte: elaboração dos autores.

Os resultados da tabela 5 denotam a condição mais grave mensurada pelo ITRA, indicando a de doenças. No entanto, devido às limitações do presente estudo, não foi possível identificar quais seriam essas doenças, tampouco verificar as consequências para a rotina de trabalho do docente participante, no que condiz ao pedido de afastamento ou atestados emitidos. Entre os respondentes, verifica-se que o fator relacionado aos 
danos físicos apresentou maior número de docentes, sendo que esse fator refere-se a sintomas como dores no corpo e distúrbios fisiológicos. Os respondentes da IES portuguesa apresentam maior percentual de docentes na condição de adoecimento em relação aos docentes participantes brasileiros.

Os fatores relacionados aos danos sociais e psicológicos também aparecem com avaliações em nível que indica presença de doenças. 0 primeiro refere-se à atitude de isolamento, dificuldades nas relações familiares e, o segundo, reflete sentimentos negativos diante da vida e de si próprio.

A análise de cluster permite agrupar os fatores que compõem o ITRA de acordo com as respostas obtidas no contexto da IES brasileira e portuguesa de forma conjunta. Foi utilizado o método de agrupamento hierárquico de Ward, no qual a formação de clusters ocorre com base nos pares mais próximos, sendo utilizadas as distâncias euclidianas. Os resultados podem ser encontrados no gráfico 1 .

Por meio do dendograma, é possivel verificar a percepção semelhante dos docentes em relação ao fator custo cognitivo, que apresentou maior similaridade entre os demais construtos (CC-BR e CC-PT). Esse resultado transcende os contextos locais e pode representar toda a categoria profissional relacionada à docência no magistério superior, cuja alta demanda cognitiva atinge nível grave. Além disso, o custo cognitivo está relacionado com outros dois fatores referentes à organização do trabalho e custo afetivo. Esse agrupamento, por sua vez, está relacionado aos fatores de vivências de prazer o trabalho como realização profissional e liberdade de expressão. Essa condição pôde ser observada em ambos os contextos.

Gráfico 1 - Análise de Cluster dos fatores do ITRA

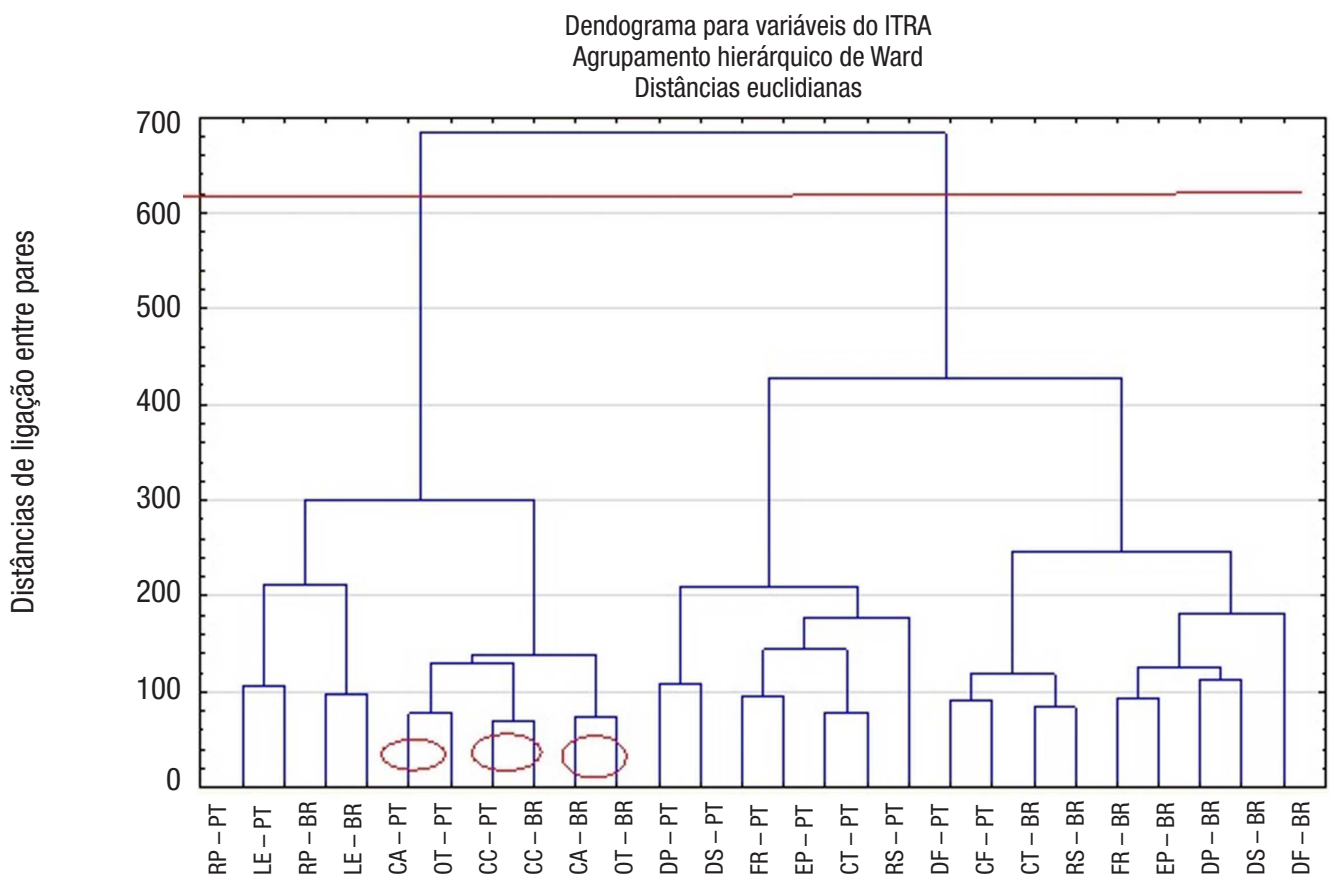

Fonte: Elaborado pelos autores com base nos dados da pesquisa. 
Mediante o corte realizado na maior altura encontrada, pôde-se verificar a formação de dois clusters distintos, visto que ambos contêm fatores pertinentes tanto ao contexto da IES brasileira quanto da IES portuguesa. Destacam-se as semelhanças evidenciadas na perspectiva de análise intrainstitucional, como: $1^{\circ}$ cluster (OT e CA; RP e LE); $2^{\circ}$ cluster (CT e RS; FR e EP; DP e DS). Adicionalmente, percebe-se o agrupamento dos fatores ligados aos danos relacionados ao trabalho com os fatores relacionados ao sofrimento no trabalho e a congruência entre condições de trabalho e relações socioprofissionais. Outro ponto comum evidenciado refere-se ao custo físico percebido de forma semelhante entre os participantes, avaliado em nível crítico.

\section{Considerações finais}

Acredita-se que o objetivo central do presente trabalho foi alcançado tendo em vista as identificações de semelhanças e diferenças em relação às vivências de prazer e de sofrimento, encontradas nas análises do contexto interinstitucional e intrainstitucional das IES brasileira e portuguesa. Nesse sentido, as contribuições permitem transcender a visão contextual acerca da dualidade entre prazer e sofrimento no trabalho docente, já que apontam questões como o adoecimento e produtivismo e trabalho imaterial, provocando a formulação de novas hipóteses e olhares sobre os temas.

Em síntese, a análise dos valores absolutos das médias de cada fator retrata realidade mais favorável aos respondentes da IES brasileira em relação aos respondentes da IES portuguesa, pois mesmo que muitos fatores tenham obtido a mesma avaliação, os docentes participantes portugueses atribuíram escores mais altos em direção à avaliação grave dos atributos.

No entanto, a análise de cluster possibilitou identificar a predominância de percepções semelhantes, no âmbito intrainstitucional, em relação às vivências de prazer o sofrimento. Quanto à perspectiva interinstitucional, destaca-se o custo cognitivo, avaliado em nível grave e agrupado no primeiro cluster reunindo a IES brasileira e portuguesa; e o custo físico agrupado no segundo cluster, avaliado em nível crítico. Esses resultados transcendem os contextos locais e podem referir-se à categoria profissional relacionada à docência no magistério superior, pertencente ao trabalho imaterial, cuja alta demanda cognitiva atinge nível grave.

Os modelos de organização do trabalho são inerentes a cada categoria organizacional, os quais coexistem fatores favoráveis ou desfavoráveis à saúde do trabalhador. A qualidade desses elementos dependerá dos interesses econômicos, ideológicos e políticos estabelecidos por quem detém a condição de ditar as regras, sejam elas tácitas ou prescritas (MENDES, 2007).

0 presente estudo apresenta limitações que residem na exclusividade quantitativa, pois a impossibilidade em termos de prazo e recursos impediu a realização da etapa qualitativa, que propiciaria confrontar ou corroborar os dados quantitativos. Da mesma forma, o questionário de autopreenchimento foi enviado no período entre final de férias e início do ano letivo de 2014. Em função disso, o número de respondentes brasileiros e portugueses não foi tão expressivo, impossibilitando que a amostra fosse obtida por 
censo, refletindo a limitação quanto à inferência dos resultados para a totalidade da população das instituições de ensino.

Sugere-se a realização de estudos adicionais que possam considerar o contexto histórico cultural entre os países em questão e a visão decorrente sobre o trabalho docente. Adicionalmente, seriam interessantes novos estudos que considerassem a perspectiva longitudinal de análise com a finalidade de mapear a variação de percepção das vivências de prazer e de sofrimento ao longo do ano letivo, a proporção de docentes pelo número de afastamentos por adoecimento, a comparação das percepções entre docentes com predileção pessoal pela atividade de ensino e pesquisa e o respectivo desempenho, favorecendo o entendimento de mecanismos individuais para a transposição do sofrimento.

Os percentuais de danos relacionados ao trabalho, na IES brasileira (30\%) e IES portuguesa (47\%), corroboram a necessidade de reflexão por mudanças dos aspectos que cercam o trabalho do docente do magistério superior. Deve-se reconhecer a sobrecarga de trabalho que esses profissionais estão submetidos. Desta forma, acredita-se que o trabalho de construção científica do conhecimento deve ser edificante em todas as áreas e que aconteça de forma natural e não mecanizada.

\section{Referências}

BIANCHETTI, Lucídio; VALLE, Ione Ribeiro. Produtivismo acadêmico e decorrências às condições de vida/ trabalho de pesquisadores brasileiros e europeus. Ensaio, Rio de Janeiro, v. 22, n. 82, p. 89-110, 2014.

BOSI, Antônio de Pádua. A precarização do trabalho docente nas instituições de ensino superior do Brasil nesses últimos 25 anos. Educação \& Sociedade, Campinas, v. 28, n. 101, p. 1503-1523, 2007.

BRASIL. Programa de apoio a planos de Reestruturação e Expansão das Universidades federais (Reuni): expansão, 2010. Brasília, DF: MEC, 2010. Disponível em: <http://reuni.mec.gov.br/expansa0>. Acesso em: 02 maio 2016.

CRUZ, Roberto Moraes, LEMOS, Jadir Camargo. Atividade docente, condições de trabalho e processos de saúde. Motrivivência, Florianópolis, n. 24, p. 59-80, 2005.

DEJOURS, Christophe. Psicodinâmica do trabalho e teoria da sedução. Psicologia em Estudo, Maringá, v. 17, n. 3, p. 363-371, 2012.

DEJOURS, Christophe; ABDOUCHELI, Elisabeth. Itinerário teórico em psicopatologia do trabalho. In: BETIOL, Marie Irene Stocco (Ed.) Psicodinâmica do trabalho: contribuições da escola dejouriana à análise da relação prazer, sofrimento e trabalho. São Paulo: Atlas, 2011. p. 119-143.

EIRAS, Margarida. Avaliação da cultura de segurança do doente em meio hospitalar: investigação ação numa unidade de radioterapia. 2011. 249f. Tese (Doutorado em Saúde Pública na especialidade de Políticas e Administração em Saúde) - Universidade Nova de Lisboa, Lisboa, 2011. 
EU-OSHA. European Agency for Safety and Health at Work. Management of psychosocial risks at work: an analysis of the findings of the European Survey of Enterprises on New and Emerging Risks (ESENER) European Risk Observatory Report. Luxembourg: Office of the European Union, 2012. Disponível em: $<$ https://osha.europa.eu/pt/tools-and-publications/publications/reports/management-psychosocial-risksesener>. Acesso em: 02 maio 2016.

FREITAS, Henrique et al. 0 método de pesquisa survey. Revista de Administração, São Paulo, v. 35, n. 3, p. 105-112, 2000.

FREITAS, Maria Ester de. A carne e os ossos do ofício acadêmico. Organizações \& Sociedade, Salvador, v. 14, n. 42, p. 187-191, 2007.

FREITAS, Maria Ester de. 0 pesquisador hoje: entre 0 artesanato intelectual e a produção em série. Cadernos EBAPE.BR, Rio de Janeiro, v. 9, n. 4, p. 1158-1163, 2011.

KOETZ, Lydia, REMPEL, Claudete, PERICO, Eduardo. Qualidade de vida de professores de instituições de ensino superior comunitárias do Rio Grande do Sul. Ciência \& Saúde Coletiva, Rio de Janeiro, v. 18, n. 4, p. 1019-1028, 2013.

LIMA, Maria de Fátima Evangelista Mendonça; LIMA-FILHO, Dario de Oliveira. Condições de trabalho e saúde do/a professor/a universitário/a. Ciências \& Cognição, Rio de Janeiro, v. 14, n. 3, p. 62-82, 2009.

MACHADO, Ana Maria Netto; BIANCHETTI, Lucídio. (Des)fetichização do produtivismo acadêmico: desafios para 0 trabalhador-pesquisador. Revista de Administração de Empresas, São Paulo, v. 51, n. 3, p. 244-254, 2011.

MAGRO, Dalva, PINTO, Maria Dias de Souza. Os efeitos da nova gestão pública na produção de conhecimento científico. Revista de Gestão e Tecnologia, Florianópolis, v. 2, n. 2, p. 78-89, 2012.

MANCEBO, Deise. Trabalho docente e produção de conhecimento. Psicologia \& Sociedade, Belo Horizonte, v. 25, n. 3, p. 519-526, 2013.

MARTINS, Andrea Arnaut Vieira, HONÓRIO, Luiz Carlos. Prazer e sofrimento docente em uma instituição de ensino superior privada em Minas Gerais. Organizações \& Sociedade, Salvador, v. 21, n. 68, p. 79-96, 2014.

MAUÉS, Olgaíses Cabral, MOTA JUNIOR, William Pessoa da. A nova regulação educacional e 0 trabalho docente na pós-graduação brasileira. Linhas Críticas, Brasília, DF, v. 17, n. 33, p. 385-402, 2011.

MENDES, Ana Magnólia. Da psicodinâmica à psicopatologia do trabalho. In: MENDES, Ana Magnolia (Org.). Psicodinâmica do trabalho: teoria, método e pesquisas. São Paulo: Casa do Psicólogo, 2007. p. 23-48.

MENDES, Ana Magnólia; FERREIRA, Mário César. Inventário sobre Trabalho e Riscos de Adoecimento - ITRA: instrumento auxiliar de diagnóstico de indicadores críticos no trabalho. In: MENDES, Ana Magnolia (Org.). Psicodinâmica do trabalho: teoria, método e pesquisas. São Paulo: Casa do Psicólogo, 2007. p. 111-125. 
NEWMAN Janet, CLARKE John. Gerencialismo. Educação \& Realidade, Porto Alegre, v. 37, n. 2, p. 353-381, 2012.

PATRUS, Roberto, DANTAS, Douglas, SHIGAKI, Helena Belintani. Produtivismo e solidariedade acadêmica: dois lados da mesma moeda? In: ENCONTRO DE ENSINO E PESQUISA EM ADMINISTRAÇÃO E CONTABILIDADE, 4., 2013, Brasília. Anais... Brasília, DF: [s. n.], 2013. Disponível em: <http://www.anpad. org.br/admin/pdf/EnEPQ177.pdf>. Acesso em: 02 ago. 2016.

PEREIRA, Júlio César Rodrigues. Análise de dados qualitativos: estratégias metodológicas para as ciências da saúde, humanas e sociais. São Paulo: Edusp, 2004.

PITA, Marina. Estresse laboral, assédio moral e burnout marcam produtivismo. Revista Adusp, São Paulo, n. 48, p. 14-21, 2010. Disponível em: <https://www.adusp.org.br/index.php/imprensa/revista-adusp/129revista-n-48-setembro-de-2010>. Acesso em: 02 maio 2016.

REG0, Teresa Cristina. Produtivismo, pesquisa e comunicação científica: entre o veneno e o remédio. Educação \& Pesquisa, São Paulo, v. 40, n. 2, p. 325-346. 2014.

SGUISSARDI, Valdemar, SILVA JÚNIOR, João dos Reis. Trabalho intensificado nas federais: pós-graduação e produtivismo acadêmico. São Paulo: Xamã, 2009.

SILVA, Isabel Cristina da, MAFRA, Flávia Luciana Naves. Trabalho docente, trabalho decente ou trabalho doente? Reflexões sobre o trabalho de professores universitários na contemporaneidade. In: ENCONTRO DE ESTUDOS ORGANIZACIONAIS DA ANPAD, 8., 2014, Gramado. Anais... Gramado: [s. n.], 2014. Disponível em: <http://www.anpad.org.br/admin/pdf/2014_EnE0175.pdf>. Acesso em: 02 maio 2016.

SPINK, Peter Kevin, ALVES, Mário Aquino. 0 campo turbulento da produção acadêmica e a importância da rebeldia competente. Organização \& Sociedade, Salvador, v. 18, n. 57, p. 337-343, 2011.

TREIN, Eunice, RODRIGUES, José. 0 mal-estar na academia: produtivismo científico, o fetichismo do conhecimento-mercadoria. Revista Brasileira de Educação, Rio de Janeiro, v. 16, n. 48, p. 769-829, 2011.

Recebido em: 30.10.2017

Revisões em: 21.08 .2018

Aprovado em: 26.10.2018

Celina Hoffmann é doutoranda em administração na Universidade Federal de Santa Maria (UFSM), no Departamento de Ciências Administrativas, na Área das Ciências Sociais Aplicadas.

Roselaine Ruviaro Zanini é professora associado II na Universidade Federal de Santa Maria (UFSM), coordenadora substituta do curso de especialização em estatística e modelagem quantitativa e atua no mestrado em engenharia de produção da UFSM. 
Gilnei Luiz de Moura é professor da graduação e pós-graduação do Departamento de Ciências Administrativas, da Área de Ciências Sociais Aplicadas, na Universidade Federal de Santa Maria.

Bárbara Parnov Machado é graduanda do curso de administração na Universidade Federal de Santa Maria, no Departamento de Ciências Administrativas, na Área das Ciências Sociais Aplicadas. 